\title{
A GESTÃO INTEGRADA DE RESÍDUOS SÓLIDOS URBANOS - PERSPECTIVA AMBIENTAL E ECONÓMICO- ENERGÉTICA
}

\author{
Jaime Filipe Borges Puna* e Bráulio dos Santos Baptista \\ Departamento de Engenharia Química, Instituto Superior de Engenharia de Lisboa, R. Cons. Emídio Navarro, 1, $1950-062$ \\ Lisboa - Portugal
}

Recebido em 29/1/07; aceito em 27/7/07; publicado na web em 19/3/08

\begin{abstract}
THE URBAN SOLID WASTE INTEGRATED MANAGEMENT - ENVIRONMENTAL AND ECONOMIC-ENERGETIC PERSPECTIVE. The importance of urban solid waste integrated systems is characterized by the several components of these systems, which are, basically, formed by physical, chemical and biological methods. This article, characterizes these methods and, which is also important, identifies the several and potential environmental impacts of those techniques. It's also extremely important to make a study of the economic rentability of those infrastructures and, also, characterize the quantitative energetic contributions of some components of these systems. This study was analysed and their results are presented in this article.
\end{abstract}

Keywords: solid waste; energy; chemistry.

\section{INTRODUÇÃO}

A gestão dos RSU é marcada pela sua complexidade, diversidade e composição. O seu tratamento e valorização tornam-se relevantes na implementação de um Sistema Integrado de Resíduos Sólidos Urbanos pelos sistemas públicos municipais ou multimunicipais de tratamento de RSU. Como caso de estudo, foi considerado neste artigo, a empresa multimunicipal Valorsul, identificada desde 1994 como exemplo pioneiro e inovador em Portugal da implementação de um sistema integrado de RSU, o qual procede à gestão e tratamento dos RSU de Lisboa, Loures, V. F. Xira, Amadora e Odivelas, com bastante sucesso. A caracterização dos impactes ambientais e energéticos associados às diversas componentes do sistema tem sido outro contributo importante da Valorsul para um melhor conhecimento científico destas questões.

\section{DESCRIÇÃO DO SISTEMA}

O Sistema de Gestão Integrada de RSU actua em duas fases importantes: A Recolha e o Tratamento e Deposição final. ${ }^{1}$

A Recolha de RSU actua nas seguintes vertentes: Recolha selectiva de matéria orgânica $\Rightarrow$ Recolha especializada; Recolha indiferenciada $\Rightarrow$ Contentores tradicionais; Recolha selectiva de materiais recicláveis $\Rightarrow$ Ecopontos + Ecocentro.

$\mathrm{O}$ tratamento e deposição final de RSU engloba a existência de unidades de valorização, tratamento (com recuperação de matéria e/ou de energia) e deposição controlada. Este conjunto de unidades pressupõe a hierarquia definida na lei, no que concerne à gestão de quaisquer resíduos sólidos ${ }^{1}$ (Figura 1).

\section{Fase de recolha}

A recolha selectiva de matéria orgânica, biodegradável, é efectuada junto de produtores em larga escala deste tipo de resíduos, nomeadamente, nos sectores da restauração, hotelaria, mercados abastecedores e retalhistas, na limpeza de jardins e outros espaços verdes. O objectivo desta recolha selectiva é obter um com-

*e-mail: jpuna@deq.isel.ipl.pt

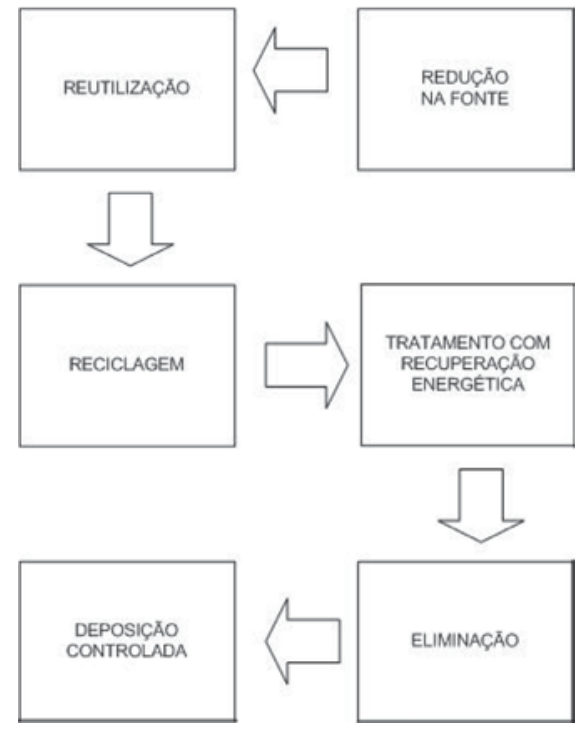

Figura 1. Etapas hierárquicas da gestão de RSU

posto orgânico sem aditivos químicos, de boa qualidade, o qual poderá ser utilizado posteriormente na agricultura, como fertilizante. A recolha indiferenciada, que corresponde aos RSU depositados nos tradicionais contentores, deve ser encaminhada para as unidades de valorização energética ou orgânica, devendo estes RSU serem objecto de um prévio processo de triagem eficiente. A recolha selectiva de materiais recicláveis pressupõe a existência no(s) município(s) abrangido(s) pelo sistema público de tratamento de RSU (municipal ou multimunicipal), de um numero significativo de Ecopontos, onde podem ser depositados os tradicionais RSU recicláveis: ${ }^{2}$ papel e cartão; vidro; embalagens (plástico e de metal); pilhas (não é RSU).

Para a deposição de outras fileiras de resíduos, nomeadamente, de grandes dimensões, mas sem prejuízo da deposição dos resíduos já referidos, o Sistema Integrado de RSU deve contemplar um Ecocentro, onde podem ser depositadas diversas fileiras de resíduos, como por exemplo, monos, óleos usados, madeiras, pilhas e 
acumuladores, resíduos de equipamentos eléctricos e electrónicos (REEE) e lâmpadas fluorescentes. ${ }^{3}$

\section{Fase de tratamento e deposição final}

Nesta fase, um sistema integrado de RSU potencialmente ideal deve contemplar as seguintes operações, interligadas entre si e discriminadas na Figura 2. ${ }^{3}$

\section{A) CENTRO DE TRIAGEM PARA VALORIZAÇÃ̃O DE RESÍDUOS RECICLÁVEIS}

B) ESTAÇÃO DE TRATAMENTO E VALORIZAÇÃO ORGĀNICA

C) CENTRAL INCINERADORA DE RESÍDUOS SÓLIDOS URBANOS

D) ESTAÇÃO DE TRATAMENTO E VALORIZAÇÃO DE ESCÓRIAS

E) ATERRO SANITÁRIO

Figura 2. Unidades constituintes de um sistema integrado de RSU

Centro de triagem para valorização de residuos recicláveis

Instalação que se destina a receber os materiais recicláveis colocados nos ecopontos onde estes são posteriormente separados por processos mecânicos e manuais, em 3 fileiras distintas: papel/ cartão; vidro; embalagens.

Após o processo de separação destes materiais, cada fileira é armazenada até expedição para a respectiva indústria recicladora. De referir que, em relação às embalagens de plástico, estas são sujeitas, devido à sua diversidade, a operações de separação em: PEAD (Polietileno de Baixa Densidade), PET (Poli-Tereftalato de Etileno), PVC (Poli-Cloreto de Vinilo) e Filme Plástico (tradicionais sacos de plástico). Observe-se a Figura 3. Por outro lado, as embalagens de metal são separadas em ferrosas e não-ferrosas (alumínio). As primeiras são separadas através de electroímans enquanto que as segundas através de correntes de Foucault. ${ }^{4}$

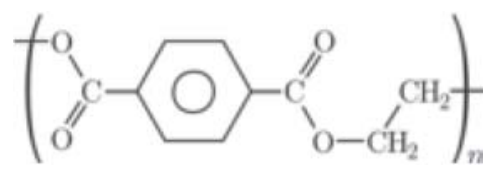

Figura 3. Fórmula de estrutura para o PET

\section{Estação de tratamento e valorização de matéria orgânica}

Permite tratar a fracção orgânica de RSU, através de métodos biológicos, obtendo-se um composto orgânico, de boa qualidade, adequado para ser utilizado na agricultura como fertilizante. Uma estação deste tipo pode ser utilizada para os seguintes métodos biológicos de tratamento: ${ }^{5}$ compostagem; digestão anaeróbica.

No processo de compostagem, após uma pré-triagem mecânica e manual dos RSU, efectua-se a degradação da matéria orgânica por digestão aeróbia. Essa pré-triagem existe com o intuito de separar os RSU recolhidos em 3 constituintes: a matéria orgânica biodegradável que se destina à câmara de compostagem, os materiais recicláveis, (ferrosos, não-ferrosos e outros) os quais são encaminhados para os recicladores e os rejeitados que seguirão para aterro.

Na câmara de compostagem, os microorganismos aí existen- tes, em presença de oxigénio e num ambiente quente e húmido, degradam a matéria orgânica dos RSU num grande armazém fechado onde, o teor de $\mathrm{O}_{2}$, a temperatura, a humidade, o $\mathrm{pH}$, o teor de matéria orgânica e a estabilidade do produto final são sistematicamente monitorizados. O ar proveniente da câmara de compostagem é caracterizado pela existência significativa de maus odores provenientes da decomposição da matéria orgânica. Para eliminar esses maus odores que constituem um impacte ambiental negativo muito significativo, o ar é desodorizado num processo conjunto de lavagem e de biofiltração sendo feita a regeneração desse ar diversas vezes ao dia e o biofiltro composto essencialmente por raízes de madeira, casca de pinheiro, argilas e areia. ${ }^{5} \mathrm{O}$ processo aeróbio é descrito genericamente pela seguinte equação química:

$$
\mathrm{C}_{\mathrm{x}} \mathrm{H}_{\mathrm{y}} \mathrm{O}_{\mathrm{z}}+\mathrm{O}_{2} \rightarrow \alpha \mathrm{CO}_{2}+\mathrm{\beta H}_{2} \mathrm{O}+\text { Novas Células }
$$

Uma outra etapa muito importante na obtenção de um composto com qualidade é a afinação onde aqui é possível efectuar a separação de mais materiais recicláveis e de rejeitados de pequenas dimensões, para além de se poderem também recolher separadamente poeiras. Todo este processo pode ser esquematizado em flowsheet (Figura 4).

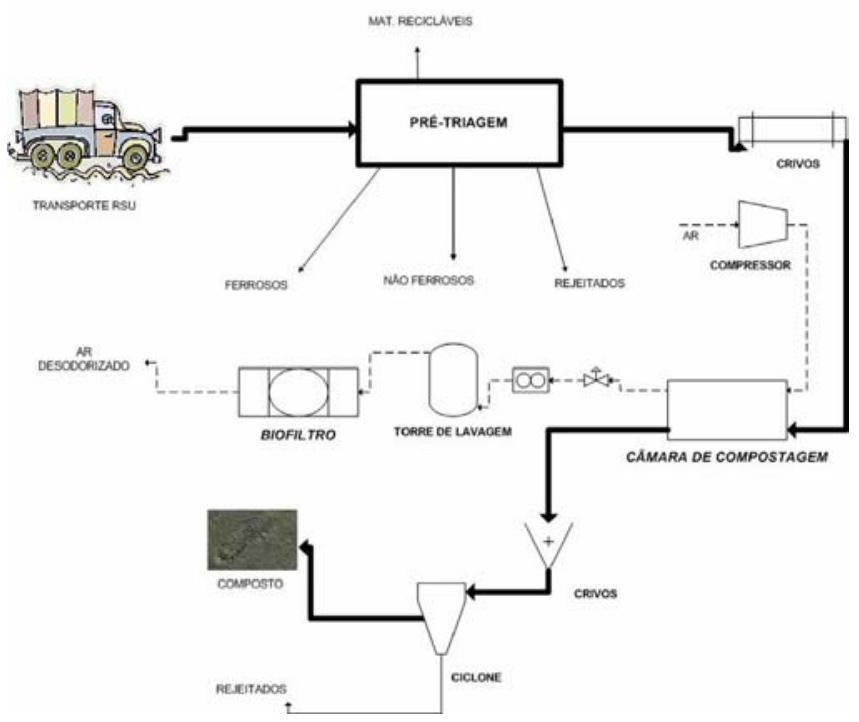

Figura 4. Diagrama processual da compostagem

A eficiência do processo global depende das condições de operacionalidade, nomeadamente das condições existentes na prétriagem e na câmara de compostagem. Os sistemas de compostagem existentes em Portugal possuem eficiências globais deste processo que vão desde $8 \%$ (Amarsul, Setúbal) até $33 \%$ (Lipor, Porto). A Central de Compostagem da Lipor (Porto) trabalha com os dados processuais indicados na Tabela $1 .^{6}$

No processo de digestão anaeróbia, a pré-triagem existente a montante dos digestores anaeróbios tem a mesma função que na compostagem, sendo separados os mesmos constituintes. Nos digestores é efectuada a degradação da matéria orgânica através da utilização de microorganismos anaeróbios, isto é, em meio isento de oxigénio e por via húmida, com os parâmetros temperatura e percentagem de humidade a serem devidamente controlados. Neste processo ocorre a formação de biogás, o qual é conduzido a um processo de cogeração, que por sua vez, está associado a uma turbina de modo a ser produzida energia eléctrica para autoconsumo da instalação ou exportando para a rede eléctrica nacional (REN). 
Tabela 1. Dados processuais da compostagem na Lipor. Reproduzida da ref. 6, com permissão da Lipor

\begin{tabular}{lccc}
\hline Recepção de RSU & 60.000 & Temperatura & $50-60{ }^{\circ} \mathrm{C}$ \\
& t/ano & na fase termófila \\
Produção de & 20.000 & pH dos RSU & $4-6$ \\
composto & t/ano & pH do \\
Caudal de ar & 410.000 & 8 \\
& $\mathrm{Nm}^{3} / \mathrm{h}$ & composto final \\
Tempo de & $\approx 60$ dias & $\%$ humidade & $\approx 40 \%$ \\
compostagem & \multicolumn{3}{c}{ do composto no } \\
& \multicolumn{3}{c}{ biofiltro } \\
\hline
\end{tabular}

Além disso, este mesmo processo conduz à obtenção, tal como na compostagem, de um composto adequado para ser utilizado na agricultura como fertilizante. ${ }^{3}$

Os digestores anaeróbios são 2 reactores biológicos em processo termófilo com 2 fases e por via húmida, onde nestes ocorre a libertação do biogás. A matéria orgânica digerida é posteriormente encaminhada para uma câmara de compostagem em ambiente rico de oxigénio onde várias renovações de ar por dia arrastam consigo os maus odores aí libertados. Para eliminar esses maus odores, o ar é sujeito a desodorização através da utilização de um biofiltro semelhante ao descrito no processo de compostagem anteriormente referido. Na Figura 5, pode-se observar um diagrama processual típico do processo de digestão anaeróbia.

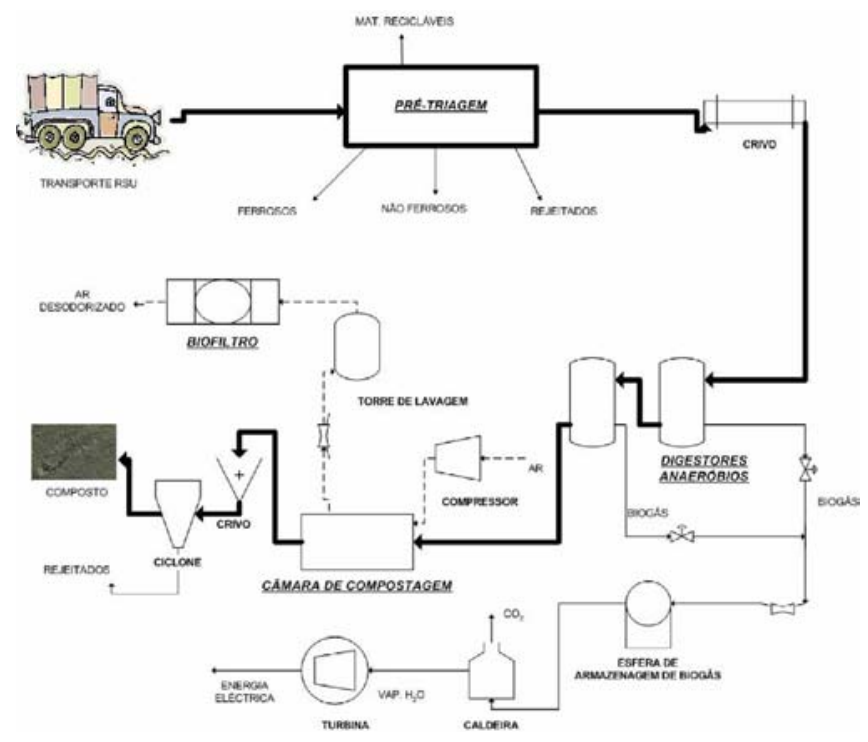

Figura 5. Diagrama processual da digestão anaeróbia

A eficiência do processo depende das condições de operacionalidade, nomeadamente das condições existentes na pré-triagem dos RSU, nos reactores biológicos, na câmara de compostagem, e na própria etapa de afinação do composto obtido. A Central de Valorização orgânica por Digestão Anaeróbia da Valorsul (Casal S. Brás, Amadora) trabalha com os dados processuais constantes na Tabela $2 .^{7}$

\section{Central incineradora de RSU}

Efectua a queima, por combustão, dos resíduos indiferenciados, os quais não são passíveis de serem reciclados. Os RSU são utilizados como combustível, sendo estes queimados com o oxigénio do ar, a temperaturas na ordem dos 900 a $1200{ }^{\circ} \mathrm{C}$. É necessário con-
Tabela 2. Dados processuais da digestão anaeróbia na Valorsul. Reproduzida da ref. 7, com permissão da Valorsul

\begin{tabular}{lccc}
\hline Recepção de RSU & $\begin{array}{c}40.000-60.000 \\
\text { t/ano }\end{array}$ & $\begin{array}{c}\text { Volume } \\
\text { biogás } \\
\text { produzido } \\
\text { Poder }\end{array}$ & $\begin{array}{c}100 \mathrm{~m}^{3} / \mathrm{t} \\
\text { RSU }\end{array}$ \\
$\begin{array}{l}\text { Produção composto } \\
\text { calorífico } \\
\text { biogás }\end{array}$ & $\begin{array}{c}\text { c/ } 65 \% \mathrm{CH}_{4} \\
\text { t/ano }\end{array}$ \\
$\begin{array}{l}\text { Energia eléctrica } \\
\text { produzida (GWh/ano) }\end{array}$ & $\begin{array}{c}\text { p/ exportação } \\
4-6\end{array}$ & $\begin{array}{c}\text { Eficiência } \\
\text { conversão } \\
\text { de energia } \\
\text { eléctrica }\end{array}$ & $30 \%$ \\
Tempo de retenção & $\begin{array}{c}\text { p/ autoconsumo } \\
\text { do composto }\end{array}$ & 13 semanas \\
\hline
\end{tabular}

trolar exaustivamente a temperatura e o tempo de arrefecimento dos gases resultantes da queima dos RSU (gases de combustão), o qual tem de ser extremamente rápido (cerca de 2 a $5 \mathrm{~s}$ ) para minimizar a formação de dioxinas e furanos, resultantes da presença de cloro nos referidos resíduos. ${ }^{2,3}$ Uma central incineradora deve estar dotada de sistemas sofisticados para o tratamento dos gases de combustão e, de uma central de co-geração, por exemplo, para produção de electricidade a partir da energia térmica existente no vapor de água sobreaquecido produzido. Tal procedimento tem em vista o aproveitamento do calor emanado pelo forno de incineração, através de caldeiras de recuperação de energia e de uma turbina para a posterior produção de energia eléctrica. A Figura 6 descreve o esquema processual típico de uma incineradora com valorização energética.

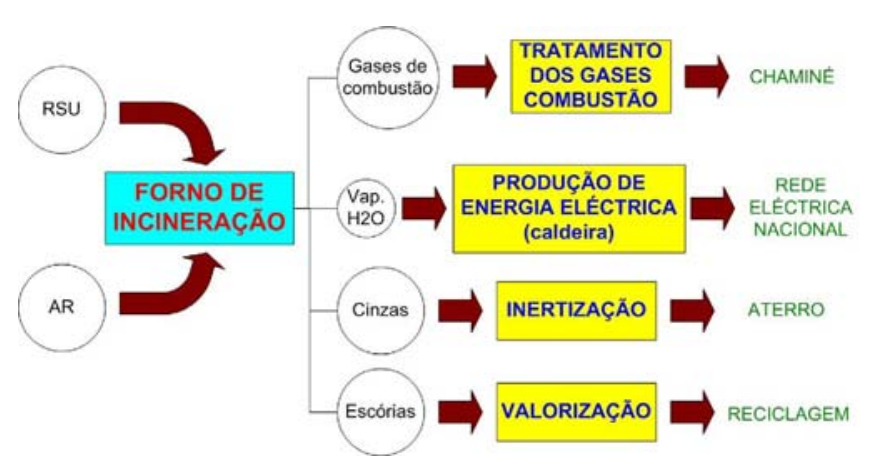

Figura 6. Diagrama processual de uma incineradora com valorização energética

Basicamente, o forno de incineração corresponde a uma câmara de combustão, onde o carbono, o hidrogénio, e o enxofre (se este último existir na composição dos RSU) são queimados para formar monóxido de carbono $(\mathrm{CO})$, dióxido de carbono $\left(\mathrm{CO}_{2}\right)$, vapor de água $\left(\mathrm{H}_{2} \mathrm{O}\right)$, dióxido de enxofre $\left(\mathrm{SO}_{2}\right)$, gases ácidos $(\mathrm{HF}, \mathrm{HCl}), \mathrm{NO}_{x}$, compostos orgânicos voláteis (COV's), dioxinas e furanos. ${ }^{8} \mathrm{As}$ reacções elementares básicas de combustão que ocorrem no forno de incineração, naturalmente, serão as seguintes:

$\mathrm{C}+1 / 2 \mathrm{O}_{2} \rightarrow \mathrm{CO} \mathrm{C}+\mathrm{O}_{2}+\rightarrow \mathrm{CO}_{2} \mathrm{H}_{2}+1 / 2 \mathrm{O}_{2} \rightarrow \mathrm{H}_{2} \mathrm{O} \mathrm{S}+\mathrm{O}_{2} \rightarrow \mathrm{SO}_{2}$

De referir que, de toda a energia eléctrica produzida numa central de incineração, 10 a $15 \%$ são suficientes para auto sustentar a própria central, sendo o restante (cerca de $80 \%$ ) enviado para a rede eléctrica nacional. ${ }^{7}$

Relativamente ao tratamento dos gases de combustão, serão 
necessários processos físico-químicos para tratar nomeadamente, $\mathrm{CO}$ (proveniente da combustão incompleta do carbono), $\mathrm{NO}_{\mathrm{x}}$ (provenientes da exposição do refractário do forno de incineração às altas temperaturas existentes no mesmo), gases ácidos ( $\mathrm{HF}, \mathrm{HCl}$ e $\mathrm{SO}_{2}$ ), metais pesados, Dioxinas/Furanos/PCB's, compostos orgânicos voláteis (COV's) e partículas. Todos estes produtos resultam da combustão incompleta dos RSU (à excepção dos $\mathrm{NO}_{\mathrm{x}}$ ), consoante a composição elementar dos mesmos, nomeadamente em termos da presença de halogéneos, como cloro e flúor, enxofre e metais pesados como $\mathrm{Cu}, \mathrm{Cr}, \mathrm{Cd}, \mathrm{Be}, \mathrm{Mn}, \mathrm{Hg}$ e As. Observe-se a Tabela 3 com as várias técnicas de tratamento dos gases de combustão normalmente utilizadas: ${ }^{9}$

Tabela 3. Processos físico-químicos utilizados no tratamento dos gases de combustão de uma incineradora

\begin{tabular}{lllr}
\hline Componente & $\begin{array}{l}\text { Técnica } \\
\text { utilizada }\end{array}$ & $\begin{array}{r}\text { Componente } \\
\text { Técnica } \\
\text { utilizada }\end{array}$ \\
\hline $\mathrm{NO}_{\mathrm{x}}$ & $\begin{array}{l}\text { Remoção selectiva não } \\
\text { catalítica com injecção } \\
\text { de sol. aquosa de amónia } \\
\text { na câmara de combustão. }\end{array}$ & $\begin{array}{l}\text { Dioxinas/ } \\
\text { Furanos/ }\end{array}$ & $\begin{array}{r}\text { Injecção } \\
\text { carvão } \\
\text { activado. }\end{array}$ \\
$\mathrm{HF}, \mathrm{HCl}, \mathrm{SO}_{2}$ & $\begin{array}{l}\text { Injecção de leite de cal } \\
\left(\mathrm{Ca}(\mathrm{OH})_{2}\right) .\end{array}$ & $\begin{array}{l}\mathrm{CO} / \\
\mathrm{COV} \text { 's }\end{array}$ & $\begin{array}{r}\text { Fornecimento } \\
\text { de } \mathrm{O}_{2} \text { na câma- } \\
\text { ra de combus- } \\
\text { tão em excesso. }\end{array}$ \\
$\begin{array}{l}\text { Metais } \\
\text { pesados }\end{array}$ & $\begin{array}{l}\text { Injecção carvão } \\
\text { activado. }\end{array}$ & $\begin{array}{r}\text { Partículas de } \\
\text { mangas. }\end{array}$ \\
\hline
\end{tabular}

A Tabela 4 mostra dados de monitorização de gases de combustão à saída da chaminé da incineradora de RSU da Valorsul (CTRSU - S. João da Talha, Loures), bem como a legislação existente em matéria de qualidade do ar. $^{7}$ Por sua vez, a Tabela 5 descreve os dados processuais mais característicos do processo de incineração de RSU da Valorsul. ${ }^{7}$

Os produtos resultantes do processo de incineração são de volume muito reduzido, pelo que são fáceis de compactar e de armazenar. Estes resíduos são classificados em inertes e em escórias, essencialmente constituídos por minerais ferrosos e não ferrosos. As cinzas são inertizadas por maturação e posteriormente depositadas em aterro controlado enquanto que as escórias, podem ser sujeitas a um processo de valorização. ${ }^{2} \mathrm{~A}$ composição típica das escórias, em peso, é a seguinte: ${ }^{7} 40 \%$ de $\mathrm{SiO}_{2}, 10$ a $20 \%$ de $\mathrm{Al}_{2} \mathrm{O}_{3}$ e $\mathrm{Fe}_{2} \mathrm{O}_{3}, 15 \% \mathrm{H}_{2} \mathrm{O}$ e óxidos, fosfatos e sulfatos com um teor conjunto inferior a $6 \%$. Relativamente às cinzas, a sua composição típica é a seguinte: ${ }^{7} 15 \%$ sulfatos, $13 \%$ cloretos, $7-8 \%$ de $\mathrm{SiO}_{2}, 4-7 \%$ de $\mathrm{Al}$ e outros metais pesados e alcalinos com um teor conjunto inferior a $5 \%$.
Estação de tratamento e valorização de escórias

Insere-se numa óptica de valorização de um subproduto, mais concretamente, das escórias resultantes da queima, por incineração, dos RSU indiferenciados. Nesta instalação, deve-se proceder à maturação destas escórias, através da sua estabilização e inertização. Após este procedimento, efectua-se a separação em inertes, materiais ferrosos e não ferrosos. ${ }^{3}$ Materiais ferrosos e não ferrosos $\Rightarrow$ Indústria recicladora; inertes $\Rightarrow$ Utilização na construção civil.

Estes inertes podem ser utilizados em obras de terraplanagem, (aterros, pavimentos, etc.), como camadas de sub-base de estradas e como material de enchimento para recuperação paisagística de pedreiras. Em termos de eficiência processual, segundo dados da Instalação de Tratamento e Valorização de Escórias da Valorsul, conseguem-se atingir taxas de recuperação até $100 \%$ do material ferroso existente nas escórias e até $70 \%$ do material não ferroso. ${ }^{7}$ Os inertes existentes nas escórias são objecto também de valorização, nomeadamente na indústria da construção civil, sendo utilizados em obras de terraplanagem para aterros e para pavimentos e ainda, como material de enchimento para recuperação de pedreiras ou de minas a céu aberto. Por sua vez, os metais ferrosos e não ferrosos obtidos provenientes das escórias são normalmente encaminhados para a indústria recicladora, tendo-se encontrado aplicações, mais concretamente, na indústria automóvel.

\section{Aterro sanitário}

Última etapa do Sistema Integrado de RSU, destina-se à deposição final, em que, os resíduos não valorizáveis por qualquer forma, são inertizados, depositados, arrumados, compactados e cobertos diariamente, em células impermeáveis, para evitar a percolação de líquidos libertados, os lixiviados. Um aterro sanitário deve ser rigorosamente controlado durante a sua fase de exploração e, após a fase de encerramento, deve-se efectuar uma recuperação paisagística adequada, continuando o aterro a ser controlado periodicamente.

O aterro sanitário controlado de RSU deve ser constituído pelas seguintes características, tal como definido no quadro legal português, pelo Decreto-Lei n. ${ }^{\circ} 152 / 02$ de 23/05: célula(s) destinada(s) aos RSU e células destinadas às cinzas inertizadas; estação de tratamento dos lixiviados; sistema de drenagem e tratamento do biogás.

Os sistemas de impermeabilização das células destinadas à deposição dos RSU indiferenciados e das cinzas inertizadas têm como objectivo evitar a possibilidade de qualquer contaminação, quer dos solos envolventes, quer de aquíferos existentes nas suas proximidades. ${ }^{7,9}$

Genericamente, ambos são constituídos pelos seguintes perfis de impermeabilização (Figura 7). ${ }^{6} \mathrm{~A}$ drenagem dos lixiviados produzidos no aterro é efectuada através de redes espinhadas de drenos

Tabela 4. Monitorização dos poluentes atmosféricos à saída da chaminé da CTRSU da Valorsul. Reproduzida da ref. 7, com permissão da Valorsul

\begin{tabular}{|c|c|c|c|c|c|c|c|c|c|}
\hline Parâm & Unidade & Port. 286/93 & CTRSU(*) & $\begin{array}{c}\text { Directiv } \\
\text { 2000/76/ } \\
\mathrm{CE}\end{array}$ & Parâm & Unidade & Port. 286/93 & CTRSU(*) & $\begin{array}{r}\text { Directiv } \\
2000 / 76 / \\
\mathrm{CE}\end{array}$ \\
\hline Partíc. & $\mathrm{mg} / \mathrm{Nm}^{3}$ & 30 & $20 / 10$ & 10 & $\mathrm{NO}_{x}$ & $\mathrm{mg} / \mathrm{Nm}^{3}$ & n.a. & 250 & 200 \\
\hline $\mathrm{HCl}$ & $\mathrm{mg} / \mathrm{Nm}^{3}$ & 50 & $20 / 20$ & 10 & $\mathrm{CO}^{x}$ & $\mathrm{mg} / \mathrm{Nm}^{3}$ & 100 & $50 / 50$ & 50 \\
\hline $\mathrm{SO}_{2}$ & $\mathrm{mg} / \mathrm{Nm}^{3}$ & 300 & $50 / 50$ & 50 & $\mathrm{COV}$ & $\mathrm{mg} / \mathrm{Nm}^{3}$ & 20 & $10 / 10$ & 10 \\
\hline $\mathrm{HF}^{2}$ & $\mathrm{mg} / \mathrm{Nm}^{3}$ & 2,0 & $1 / 0,8$ & 1 & $\begin{array}{l}\text { Diox./ } \\
\text { Furan. }\end{array}$ & $\begin{array}{c}\mathrm{ng} / \mathrm{Nm}^{3} \\
\mathrm{TEQ}\end{array}$ & n.a. & $0,1 / 0,05$ & 0,1 \\
\hline
\end{tabular}

(*) - Licença CTRSU da Valorsul/valores de compromisso CTRSU da Valorsul 
Tabela 5. Dados processuais do processo de incineração na Valorsul. Reproduzida da ref. 7, com permissão da Valorsul

\begin{tabular}{|c|c|c|c|}
\hline $\begin{array}{l}\text { Temperatura } \\
\text { do forno }\end{array}$ & $900-1200{ }^{\circ} \mathrm{C}$ & $\begin{array}{l}\text { Produção } \\
\text { de cinzas }\end{array}$ & $\begin{array}{c}30 \mathrm{~kg} / \mathrm{t} \\
\mathrm{RSU}\end{array}$ \\
\hline $\begin{array}{l}\text { Poder Calorífico } \\
\text { nominal dos RSU }\end{array}$ & $\begin{array}{c}7600-7900 \\
\mathrm{~kJ} / \mathrm{kg}\end{array}$ & $\begin{array}{c}\text { Produção de } \\
\text { energia } \\
\text { eléctrica }\end{array}$ & $\begin{array}{c}587 \mathrm{kwh} / \mathrm{t} \\
\mathrm{RSU} ; \\
\text { fornecimento } \\
\text { a } 150.000 \\
\text { habitantes. }\end{array}$ \\
\hline Recepção RSU & 662000 t/ano & Vapor de água & $\begin{array}{c}\text { Sobreaq. } \\
\left(\mathrm{T}>300^{\circ} \mathrm{C}\right)\end{array}$ \\
\hline $\begin{array}{l}\text { Produção de } \\
\text { escórias }\end{array}$ & $200 \mathrm{~kg} / \mathrm{t} \mathrm{RSU}$ & $\begin{array}{l}\text { Potência } \\
\text { da turbina }\end{array}$ & $\begin{array}{c}\text { Condensação, } \\
50 \mathrm{MW} \text {. }\end{array}$ \\
\hline
\end{tabular}

que os conduzem, por gravidade e, através de uma central de bombagem, a uma Estação de Tratamento de Lixiviados (ETL) onde é efectuado o tratamento destes. A Tabela 6 apresenta dados característicos do afluente da ETL do Aterro da Valorsul (Mato da Cruz, V. F. Xira). ${ }^{7}$ Por sua vez, a linha processual de uma ETL é constituída por uma série de etapas, as quais podem ser sistematizadas na Tabela 7.8

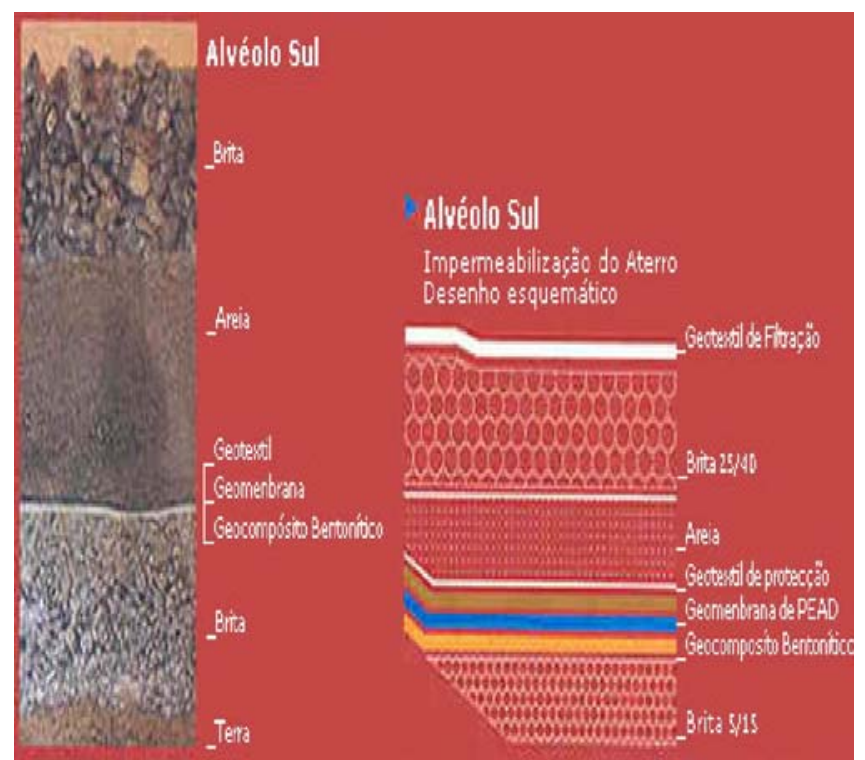

Figura 7. Sistema de impermeabilização da célula de deposição de RSU no aterro da Lipor, Porto. Reproduzida da ref. 6, com permissão da Lipor

A drenagem do biogás produzido nas células de aterro (com composição volumétrica média de $55 \% \mathrm{CH}_{4}, 45 \% \mathrm{CO}_{2}$ ) é efectuada através da condução do mesmo para um queimador, controlando o seu caudal. A queima do biogás conduz à libertação de $\mathrm{CO}_{2}$ e de vapor de água, segundo a equação química $\mathrm{CH}_{4}+\mathrm{O}_{2} \rightarrow \mathrm{CO}_{2}+\mathrm{H}_{2} \mathrm{O}$. A temperatura do queimador atinge normalmente os $1100{ }^{\circ} \mathrm{C}$ com uma pressão total de aproximadamente $300 \mathrm{mbar}$. O caudal de biogás no Aterro da Valorsul (Mato da Cruz, V. F. Xira) chega a atingir os $500 \mathrm{~m}^{3} / \mathrm{h}^{7}$ Sendo a queima um processo de combustão exoenergético, ocorre a libertação de energia para o exterior. Esta energia libertada é significativa, pois o poder calorífico (PC) do biogás corresponde 50 a $60 \%$

Tabela 6. Características do lixiviado da ETL da Valorsul. Reproduzida da ref. 7, com permissão da Valorsul

\begin{tabular}{lc}
\hline Caudal Médio $\left(\mathrm{m}^{3} / \mathrm{dia}\right)$ & 166 \\
{$\left[\mathrm{CBO}_{5}\right]\left(\mathrm{mg} \mathrm{O}_{2} / \mathrm{L}\right)$} & 764 \\
{$[\mathrm{CQO}]\left(\mathrm{mg} \mathrm{O}_{2} / \mathrm{L}\right)$} & 1900 \\
\hline
\end{tabular}

Tabela 7. Linha processual de uma ETL

\begin{tabular}{|c|c|c|}
\hline Medição caudais & & \\
\hline $\begin{array}{l}\text { Pré-Tratamento } \\
\text { Tratamento } \\
\text { biológico }\end{array}$ & $\begin{array}{c}\text { Adição de } \mathrm{H}_{3} \mathrm{PO}_{4} \text {. } \\
\text { Lagoas estabilização } \\
\text { Nitrificação/ } \\
\text { Desnitrificação; }\end{array}$ & $\begin{array}{c}\text { Decantação } \\
\text { biológica }\end{array}$ \\
\hline $\begin{array}{l}\text { Tratamento } \\
\text { físico-químico }\end{array}$ & $\begin{array}{c}\text { Floculação c/ } \mathrm{FeCl}_{3} \\
\text { e polielectrólito; } \\
\text { Neutralização; }\end{array}$ & $\begin{array}{l}\text { Ultra-filtração } \\
\text { Osmose inversa; }\end{array}$ \\
\hline Tratamento lamas & $\begin{array}{c}\text { Espessamento; } \\
\text { Desidratação } \\
\text { mecânica; }\end{array}$ & $\begin{array}{l}\text { Condicionamento } \\
\text { com polielectrólito }\end{array}$ \\
\hline
\end{tabular}

do poder calorífico do gás natural, a que corresponde um valor de PC compreendido entre 21500 a $23000 \mathrm{~kJ} / \mathrm{kg} .{ }^{10}$

Numa óptica de valorização energética, cada vez mais importante como meta de sustentabilidade ambiental sem deixar de potenciar o tão necessário e fundamental desenvolvimento sócio-económico, a par das directrizes políticas comunitárias em matéria de eficiência energética, o aproveitamento da energia libertada pela queima do biogás consiste na extracção deste das células de aterro para motores geradores de energia eléctrica, queimando o excedente.

De referir que, a eficiência deste processo se situa nos 33 a $40 \%$, isto é, de $100 \%$ do biogás fornecido, só entre 33 a $40 \%$ se destina à produção de energia eléctrica. A restante percentagem destina-se a calor existente no excedente do biogás que é queimado $(50 \%)$ sendo o restante para perdas de energia que ocorrem durante este processo. ${ }^{11}$ A título de exemplo, o aterro sanitário da Amarsul, no Seixal, consegue-se que $1 \mathrm{~m}^{3}$ de biogás com 55\% metano origine 5,6-6,9 $\mathrm{kWh}$ de electricidade, sendo que o caudal de RSU depositado em aterro é cerca de 146000 t/ano, produzindose $14880 \mathrm{MWh}$ de energia eléctrica. ${ }^{10}$ A Figura 8 indica-nos as etapas constituintes de um sistema de aproveitamento do biogás produzido num aterro sanitário, mais concretamente, no aterro sanitário da Amarsul, no Seixal. ${ }^{10}$

Como exemplo pioneiro e inovador da implementação de um sistema integrado de RSU, há mais de 10 anos em Portugal, tem-se o sistema integrado da Valorsul, esquematizado na Figura 9. ${ }^{7}$ Para além do Sistema Integrado da Valorsul que opera na área metropo-

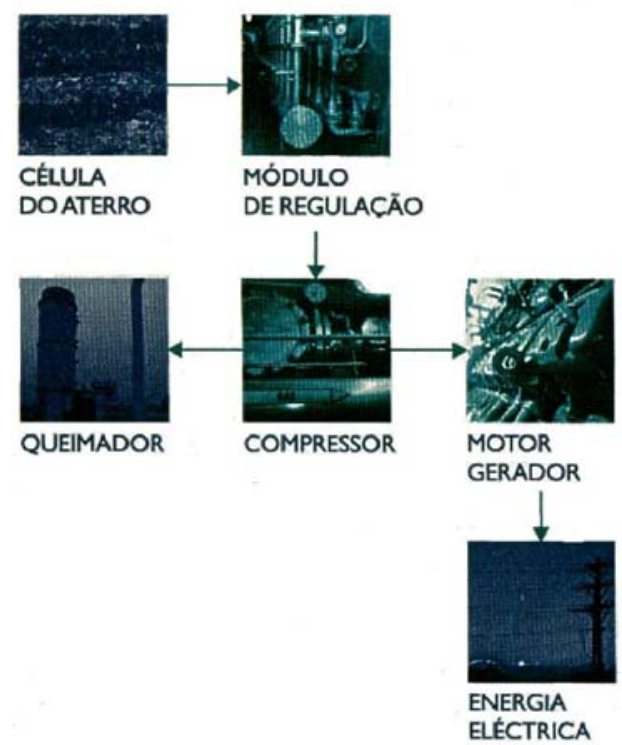

Figura 8. Sistema de aproveitamento do biogás no aterro sanitário do Seixal da Amarsul 


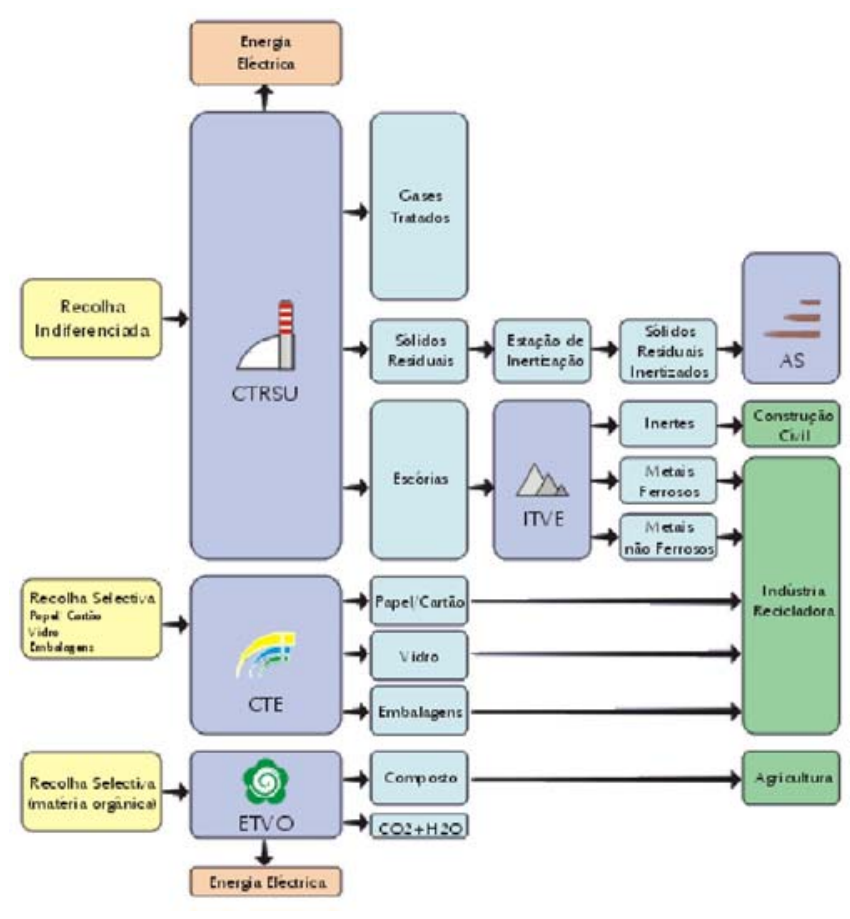

Figura 9. Sistema integrado de gestão de RSU da Valorsul. Reproduzida da ref. 7, com permissão da Valorsul

litana de Lisboa, existe mais um sistema integrado de RSU desta natureza, que corresponde ao Sistema Integrado da Lipor, o qual se localiza na área metropolitana do Porto. ${ }^{6}$

\section{IMPACTES AMBIENTAIS ASSOCIADOS}

Em cada etapa deste sistema integrado, existem impactes ambientais associados, os quais devem ser contabilizados e analisados por forma a se ter, por um lado, conhecimento das melhores condições operatórias das várias unidades e, por outro lado, estar de acordo com a legislação vigente em matéria de tratamento de RSU e de análise de impacte ambiental e, finalmente, mas não menos importante, assegurar um ambiente sustentável para toda a comunidade envolvente, nomeadamente as populações e o meio ambiente, que são os grandes beneficiados com a implementação deste sistema. ${ }^{12}$ Como principais impactes ambientais a ter em conta na avaliação de impacte ambiental de cada uma das unidades do sistema integrado, destacam-se os seguintes: ${ }^{13-16}$ ruído proveniente dos equipamentos mecânicos e do intenso tráfego dos camiões de descarga dos RSU; má qualidade do ar e das emissões atmosféricas, as quais devem ser tratadas na instalação e monitorizadas à saída; presença de odores e cheiros nauseabundos provenientes dos processos biológicos; má qualidade da água e dos efluentes emitidos pelas várias unidades, os quais devem ser tratados e monitorizados na própria unidade; formação de subprodutos e de resíduos de reduzidas dimensões, essencialmente na incineradora, os quais devem ser valorizados; eventuais problemas de saúde pública nas proximidades das várias unidades de tratamento do sistema integrado de RSU (incineradora, central de valorização orgânica e aterro), se não forem adoptados os mecanismos de prevenção e tratamento das várias emissões líquidas e atmosféricas provenientes destas unidades. Será necessário implementar um programa de vigilância e monitorização da saúde pública nas proximidades dessas instalações; má recepção e incorrecta percepção, por parte das comunidades populacionais envolventes, do objectivo e do funcio- namento das várias unidades do sistema integrado de RSU, a qual terá de ser analisada através da avaliação da atitude psicossocial dessas populações; possibilidade de ocorrerem acidentes graves, os quais devem ser prevenidos, apostando devidamente na implementação de medidas e procedimentos que visem a segurança dos trabalhadores e dos locais de trabalho; localização inadequada das várias unidades do sistema, originando impactes ambientais e sócio-económicos que porventura possam ser evitados se existir alternativa de localização mais apropriada; como impacte positivo, deve ser considerado a valorização energética obtida através da produção de energia eléctrica nas incineradoras, centrais de digestão anaeróbia e no aproveitamento do biogás gerado nas células de deposição dos aterros.

\section{ESTRATÉGIAS DE REDUÇÃO DE RESÍDUOS}

Em termos de planos estratégicos de redução de RSU, há a destacar o PERSU (Plano Estratégico de Resíduos Sólidos Urbanos) e a Estratégia Nacional para a Redução de Resíduos Urbanos Biodegradáveis destinados a Aterro. A implementação de um Sistema Integrado de Gestão de RSU pressupõe a incorporação das filosofias de redução, reutilização e reciclagem subjacentes a estes dois planos estratégicos. De facto, a estratégia do PERSU baseiase na aplicação de uma hierarquia de princípios em que a prevenção (redução e reutilização) surge em $1^{\circ}$ lugar nessa estrutura hierárquica, seguida da valorização (reciclagem e recuperação energética) e, finalmente, do confinamento seguro em aterro. Os objectivos do PERSU enquadram-se perfeitamente nos objectivos de concepção e funcionamento de um Sistema Integrado de Gestão de RSU, estruturados da seguinte maneira: ${ }^{17}$ conseguir que toda a população passe a ser servida por unidades de tratamento adequadas, alcançando-se dessa forma níveis de serviço honrosos em termos europeus; promover a redução dos quantitativos de resíduos a depositar em aterro, destinando-se este, progressivamente, a resíduos resultantes de outros métodos de tratamento; promover a redução da carga orgânica dos resíduos a depositar em aterro; promover a redução das emissões de GEE (gases com efeito de estufa), nomeadamente $\mathrm{CO}_{2}$ e $\mathrm{CH}_{4}$; melhorar a qualidade dos RSU, por via da separação dos componentes perigosos neles contidos.

O PERSU traçou um cenário de produção de RSU que visava um crescimento anual de $2 \%$ na produção de RSU de 1998 até 2006, atingindo-se neste último ano as $4648 \mathrm{kt}$ de RSU produzidos. No entanto, verificava-se já em 2002 uma capitação de RSU superior em relação ao cenário PERSU em cerca de 324 kt, a que corresponde um desvio em relação aos objectivos traçados na ordem dos $7 \%$, com tendência para aumentar. ${ }^{18}$

Por outro lado, a gestão dos resíduos urbanos biodegradáveis (RUB) contidos nos RSU reveste-se da maior importância, já que constituem uma percentagem significativa dos RSU produzidos, cerca de $60 \%$. Consideram-se como RUB, os resíduos urbanos que possam ser sujeitos a decomposição aeróbia ou anaeróbia, i.e., a fracção orgânica de RSU, como por exemplo, resíduos alimentares e de jardim e, também, o papel e cartão. ${ }^{8,9}$ É preciso ter em linha de conta que, os RUB apresentam sérias implicações ao nível da exploração de aterros, tais como: ${ }^{19,20}$ a produção de biogás, a qual, por um lado, inclui na sua composição gás metano $\left(\mathrm{CH}_{4}\right)$ e dióxido de carbono $\left(\mathrm{CO}_{2}\right)$, gases estes que contribuem em muito para o efeito de estufa e para a produção de odores desagradáveis e, por outro lado, pode em determinadas proporções de mistura com o oxigénio do ar, apresentar risco de explosão, através da reacção de combustão $\mathrm{CH}_{4}+\mathrm{O}_{2} \rightarrow \mathrm{CO}_{2}+\mathrm{H}_{2} \mathrm{O}$, a qual liberta energia em quantidade significativa; a produção de lixiviados com elevada carga orgânica, com potencial impacte ao nível da qualidade das águas 
superficiais e subterrâneas; a utilização de espaço destinado à deposição de resíduos; a ocorrência de assentamentos da massa de resíduos.

Além disso, no caso do papel e cartão, trata-se de um recurso valorizável através de reciclagem e, no caso da matéria orgânica, é valorizável através da produção de energia e/ou de composto útil para a agricultura. Por este conjunto de razões, desde logo se constata que existe a necessidade imperiosa de reduzir a deposição de RUB em aterro. Essa necessidade vem contemplada na Directiva Aterros (Directiva 1999/31/CE do Conselho de 26/04, transposta pelo Decreto-Lei português n. ${ }^{\circ} 152 / 2002$ de $23 / 05$ ) que estabelece a necessidade de definição de uma estratégia nacional nesta matéria. Assim sendo, foi elaborada pelo Ministério do Ambiente e Ordenamento do Território, através do Instituto Nacional dos Resíduos, a Estratégia Nacional para a Redução dos RUB destinados a Aterros. Os princípios orientadores desta estratégia são os seguintes: ${ }^{19,20}$ recolha selectiva da matéria orgânica; construção de novas unidades de valorização (compostagem e digestão anaeróbia); optimização das unidades existentes/a construir; produção gradual de composto a partir da recolha selectiva da matéria orgânica; garantia da qualidade do composto; minimização da deposição de RUB em aterro.

Na Tabela 8, são apresentadas as metas quantitativas para a deposição de RUB em aterros, delineadas nesta estratégia. ${ }^{19} \mathrm{De}$ facto, a implementação de unidades de valorização orgânica (compostagem e/ou digestão anaeróbia) vem ao encontro dos pressupostos definidos na estratégia de redução de RUB em aterro. Deste modo, num futuro próximo, os vários sistemas de tratamento de RSU devem todos caminhar neste sentido, implementando unidades desta natureza em detrimento da abertura de novas células de deposição nos aterros controlados. As Figuras 10 e 11 apresentam a evolução prevista para a produção de RSU até 2016, bem como os quantitativos de matéria orgânica e os objectivos a atingir na redução da deposição de RUB em aterros. ${ }^{19}$

\section{PERSPECTIVA ECONOMICO-ENERGÉTICA DAS INFRA- ESTRUTURAS DE TRATAMENTO DE RSU}

Importa agora proceder a uma rápida análise económica sobre várias opções de sistemas integrados de gestão de RSU, efectuando uma comparação entre os investimentos totais necessários para a

Tabela 8. Metas para a redução da deposição de RUB em aterro, relativamente a 1995

\begin{tabular}{lc}
\hline DATA & $\%$ admissível de RUB em aterro \\
\hline Janeiro 2006 & 75 \\
Janeiro 2009 & 50 \\
Janeiro 2016 & 35 \\
\hline
\end{tabular}

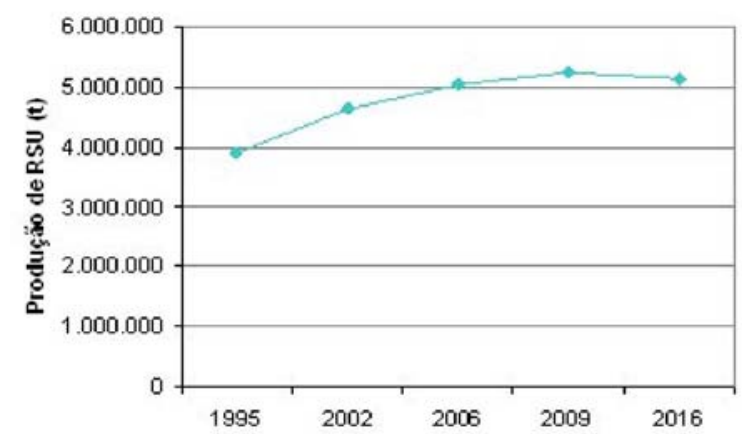

Figura 10. Evolução prevista para a produção total de RSU

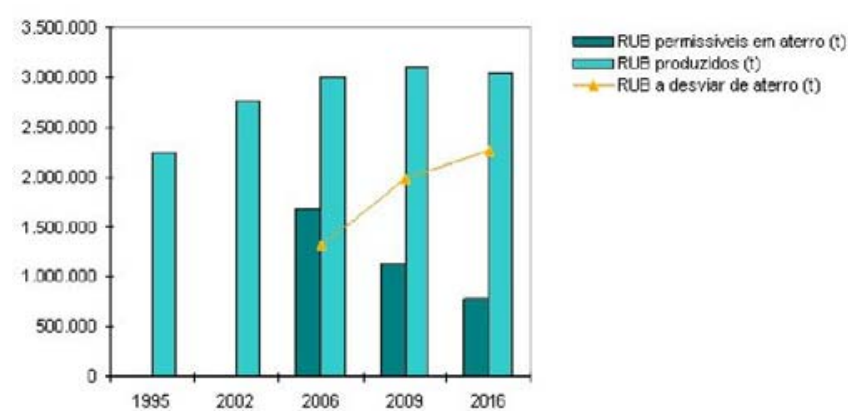

Figura 11. Evolução da produção de RUB e objectivos a atingir na redução da deposição de RUB em aterro

implementação de cada uma dessas opções bem como de tarifas de equilíbrio (receitas) a serem cobradas por esses sistemas. Segundo o Relatório Final de um Estudo Comparativo sobre Custos de Soluções de Tratamentos e Destino Final de RSU, elaborado por uma equipa de 7 docentes/investigadores da Faculdade de Ciências e Tecnologia da Universidade Nova de Lisboa (FCT/UNL) para o Instituto dos Resíduos, em Junho de 2004, estipularam-se várias opções de implementação de sistemas integrados de gestão de RSU, enunciadas na Tabela 9.21

Tabela 9. Opções de sistemas integrados de gestão de RSU considerados

\begin{tabular}{lc}
\hline Cenário & Elementos constituintes $^{1}$ \\
\hline 1 & Triagem + Central de Valorização Orgânica ${ }^{2}+$ Aterro \\
2 & Triagem + Central de Valorização Orgânica + Aterro \\
& + Incineração \\
$3 \mathrm{a}$ & Triagem + Central de Valorização Orgânica + Aterro \\
& + Tratamento Mecânico-Biológico \\
$3 \mathrm{~b}$ & Triagem + Central de Valorização Orgânica + Aterro \\
& + Tratamento Mecânico-Biológico + Incineração \\
\hline${ }^{1}-$ Todos os sistemas incluem recolha indiferenciada e selectiva. ${ }^{2}$ \\
${ }^{-}$Compostagem ou Digestão Anaeróbia + Compostagem
\end{tabular}

De referir que o Tratamento Mecânico-Biológico corresponde a uma componente adicional dos sistemas integrados e visa proceder à valorização material de algumas fileiras específicas de resíduos sólidos e/ou à deposição segura em aterro dessas fileiras. Citando o mesmo estudo, foram analisados todos os tipos de custos inerentes à construção e instalação de infra-estruturas desta natureza, nomeadamente, custos operatórios, custos com pessoal, custos com consumíveis, etc. e inventariação das receitas atribuídas às entidades exploradoras destes sistemas, as quais, recorde-se, funcionam a título de concessão. Contabilizando todos estes custos, foram determinados os custos totais de investimento para os vários cenários traçados na Tabela 9. Esses custos são indicados na Tabela 10 e Figura 12. Por outro lado, As tarifas de equilíbrio estão sintetizadas na Tabela 11 e Figura 13.

A nível da valorização energética pode-se referir que, atendendo à descrição dos vários métodos de tratamento de RSU, a incineração, a digestão anaeróbia da fracção orgânica dos resíduos e o aproveitamento do biogás gerado em aterros são as componentes do sistema integrado que contribuem para uma valorização energética significativa através da produção de energia eléctrica, a qual, para além de autonomizar as próprias instalações, exporta ainda para a rede eléctrica nacional, um quantitativo energético considerável. ${ }^{5,21}$ Observe-se a Tabela $12.7,10$ 
Tabela 10. Custos de investimento para cada opção de sistema integrado de gestão de RSU

\begin{tabular}{lcc}
\hline Cenário & \multicolumn{2}{c}{ Investimento $\left(10^{6} \bullet\right)$} \\
& C/ Dig. Anaeróbia & C/ Compostagem \\
\hline 1 & 76 & 63 \\
2 & 202 & 195 \\
$3 \mathrm{a}$ & 106 & 99 \\
$3 \mathrm{~b}$ & 210 & 203 \\
\hline
\end{tabular}

\section{Custos de Investimento $\left(10^{\wedge} 6 €\right)$}

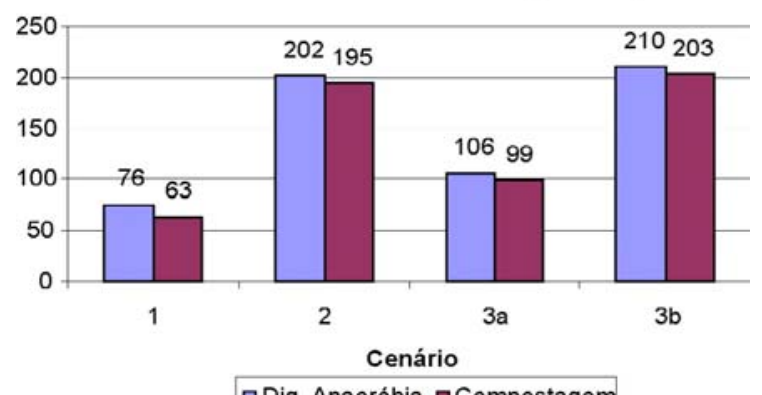

口Dig. Anaeróbia uCompostagem

Figura 12. Custos de investimento para cada cenário de sistema integrado de $R S U$

Tabela 11. Tarifas de equilíbrio para cada opção de sistema integrado de gestão de RSU

\begin{tabular}{lcc}
\hline Cenário & \multicolumn{2}{c}{ Tarifa equilíbrio $(\bullet / t /$ RSU $)$} \\
& C/ Dig. Anaeróbia & C/ Compostagem \\
\hline 1 & 14.92 & 15.56 \\
2 & 26.50 & 26.28 \\
$3 \mathrm{a}$ & 15.27 & 15.07 \\
$3 \mathrm{~b}$ & 20.97 & 20.76 \\
\hline
\end{tabular}

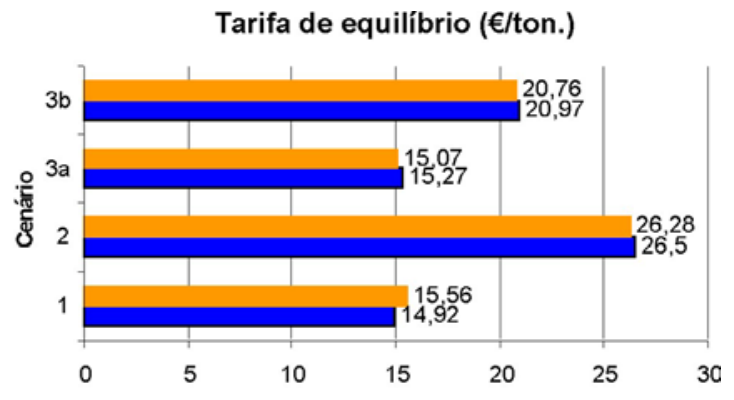

-Dig. Anaeróbia = Compostagem

Figura 13. Tarifa de equilíbrio para cada cenário de sistema integrado de $R S U$

A partir destes dados e, atendendo a que na incineração (Valorsul, 2006), por cada tonelada de RSU incinerada são produzidos $587 \mathrm{kWh},{ }^{7}$ podem ser determinadas as produções de energia eléctrica nominais para cada método de valorização energética referido. Esses valores estão indicados na Tabela 13 e na Figura 14 e permitem efectuar uma comparação em termos de energia eléctrica nominal produzida. ${ }^{7}$

Evidentemente que, nem toda a energia eléctrica produzida é exportada para a rede eléctrica nacional, pois uma determinada
Tabela 12. Produção de RSU anual e energia eléctrica anual produzida nos vários métodos de tratamento de RSU

\begin{tabular}{lcc}
\hline Métodos de tratamento de RSU & t RSU/ano & MWh/ano \\
\hline Incineração & 662000 & 388594 \\
digestão anaeróbia $^{\mathrm{a}}$ & 40000 & 12000 \\
Aproveitamento energético do $^{\text {biogás em aterros }}{ }^{\mathrm{b}}$ & 146000 & 14880 \\
\hline
\end{tabular}

a - Central de Valorização orgânica da Valorsul. b - Aterro da Amarsul (Seixal)

Tabela 13. Produções nominais de energia eléctrica para cada método de valorização energética de RSU

\begin{tabular}{lcc}
\hline Método tratam. & $\mathrm{kWh} / \mathrm{t}$ RSU & Eficiência(\%) \\
\hline Incineração & 587 & - \\
Dig. anaeróbia & 300 & 30 \\
Aprov. biogás em aterros & 102 & 40 \\
\hline
\end{tabular}

\section{Produção nominal de energia eléctrica} (kWh/ton. RSU)

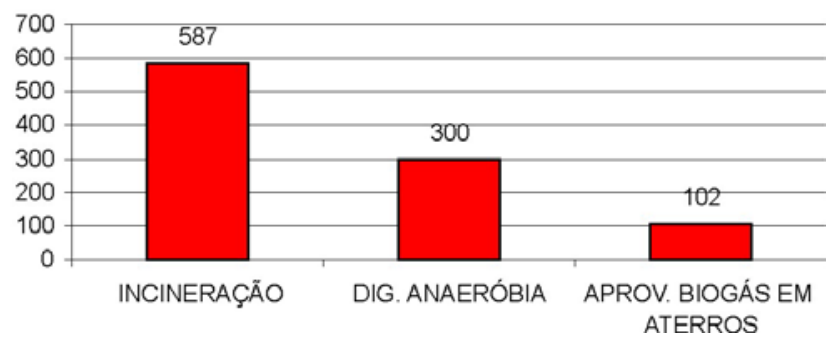

Figura 14. Produção nominal de energia eléctrica para cada método de valorização energética de $R S U$

percentagem servirá para cobrir as necessidades eléctricas das próprias unidades de tratamento, o que as torna autónomas do ponto de vista de dependência energética do exterior. A Tabela 14 sumariza, para os vários métodos de tratamento de RSU considerados, a distribuição da energia eléctrica produzida. ${ }^{22}$

Tabela 14. Distribuição da energia eléctrica produzida pelos vários métodos de tratamento e valorização de RSU

\begin{tabular}{lcc}
\hline $\begin{array}{l}\text { Método de tratamento } \\
\text { de RSU }\end{array}$ & $\begin{array}{c}\% \text { para consumo } \\
\text { próprio }\end{array}$ & $\begin{array}{c}\% \text { de exportação } \\
\text { para REN }\end{array}$ \\
\hline Incineração & $15-20$ & $80-85$ \\
Dig. anaeróbia & $30-35$ & $65-70$ \\
Aprov. biogás em aterros & $5-10$ & $90-95$ \\
\hline
\end{tabular}

Em função destes dados, pode-se estimar a produção anual de energia eléctrica exportada e vendida para a rede eléctrica nacional (REN) e as correspondentes receitas anuais para as entidades exploradas destes sistemas integrados de RSU, atendendo a que o preço de compra do $\mathrm{kWh}$ produzido é de $0,07 \bullet,{ }^{21}$ considerando que estes métodos possuem a montante, componentes de valorização material de modo a não colocar em causa a política de redução, reutilização e reciclagem material de fileiras específicas de resíduos. Esta tarifa é designada por tarifa verde e, atendendo à filosofia de gestão dos RSU nos sistemas integrados, esta valorização material é perfeitamente conseguida aplicando operações de triagem 
Tabela 15. Energia eléctrica anual exportada para a REN e receitas anuais obtidas com a venda dessa energia

\begin{tabular}{lcc}
\hline Método tratam. & MWh/ano & $10^{6} \bullet$ \\
\hline Incineração & 310875 & 21,76 \\
Dig. anaeróbia & 8000 & 0,56 \\
Aprov. biogás em aterros & 14135 & 0,99 \\
\hline
\end{tabular}

\section{Energia eléctrica anual exportada para a R.E.N.}

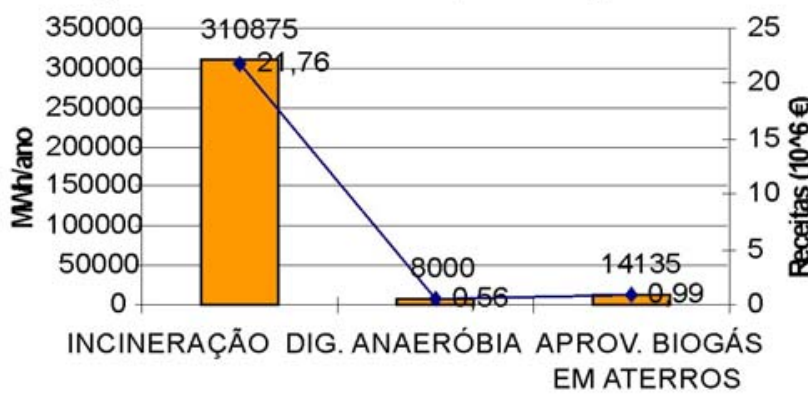

\section{Receitas $\left(10^{\wedge} 6 €\right) \rightarrow-M W h / a n o$}

Figura 15. Energia eléctrica anual exportada para a REN e receitas anuais obtidas com a venda dessa energia

mecânica e manual, tal como se pode constatar pela Tabela 15 e Figura 15.

\section{CONCLUSÕES FINAIS}

É importante realçar, em jeito de conclusão, várias considerações importantes: a implementação de um sistema integrado de gestão de RSU contempla duas fases distintas, igualmente importantes: a recolha de RSU e a sua valorização, tratamento e deposição final; a adopção de um sistema integrado visa estipular uma solução para cada fileira de RSU, de acordo com a legislação existente e com as tecnologias actualmente disponíveis. Visa também criar mecanismos de aplicação da gestão hierárquica de resíduos, definida na Lei-Quadro da Gestão de Resíduos (DL n. ${ }^{\circ}$ 178/2006 de 05/09): redução, reutilização, reciclagem, valorização energética, eliminação e deposição final, ${ }^{23}$ a existência de um sistema bem definido de recolha selectiva e a implementação de fases de triagem a montante dos vários métodos de tratamento, juntamente com a garantia de canais de escoamento dos materiais recicláveis junto da indústria recicladora, garante um aumento da capitação de RSU recolhido selectivamente, bem como uma maior eficiência do sistema; uma mais-valia importante do sistema integrado consiste na valorização de subprodutos, como é o caso, por exemplo, da valorização das escórias resultantes da incineração; um sistema integrado de RSU permite, através de quantitativos de RSU significativos, colhidos por vários municípios, rentabilizar o próprio sistema, a par de eventuais valorizações energéticas, com produção de energia eléctrica, o que lhe permite criar autonomia em termos de custos com electricidade; ${ }^{24}$ é na incineração que se consegue produzir e exportar maior quantidade de energia eléctrica para a REN e, simultaneamente, obter maior volume de receitas com essa exportação para as entidades exploradoras dos sistemas integrados de gestão de RSU. Note-se que, dos 3 métodos indicados de produção de energia eléctrica a partir do tratamento dos RSU, a incineração por si só corresponde a $93 \%$ do total de energia eléctrica exportada para a REN; é na incineração que a produção de energia eléctrica nominal é substancialmente maior, seguida da digestão anaeróbia e, por fim, do aproveitamento energético do biogás em aterros; no entanto, tal não significa que, em função destes resultados, todos os sistemas integrados de gestão tenham de conter uma incineradora de RSU, pois a rentabilidade da mesma só é possível para um caudal de RSU muito significativo. Note-se que os custos de investimento na construção de um sistema integrado com incineradora duplicam, no mínimo, do que os custos de investimento em sistemas integrados sem incineradora; ${ }^{21}$ a incineradora só deve existir em sistemas multimunicipais e em comunidades urbanas muito significativas. Além disso, a montante, devem existir mecanismos claros de aposta na reciclagem material de fileiras de RSU indiferenciados; a adopção de um sistema integrado de RSU, garante maior eficácia e mais rentabilidade aos sistemas públicos multimunicipais, atendendo à sua abrangência territorial, bem como à concepção do próprio sistema, com as etapas de recolha, tratamento e deposição final, sem esquecer evidentemente a optimização dos custos de transporte e a existência de estações de transferência de RSU; a identificação dos impactes ambientais associados às várias etapas do sistema integrado e a criação de mecanismos que permitam minimizar ou mesmo anular esses mesmos impactes, cria uma mais-valia ambiental para todas as comunidades envolventes, contribuindo deste modo para a prossecução do desenvolvimento sustentável $;{ }^{16}$ considerando que dos 30 sistemas públicos municipais e multimunicipais de gestão e tratamento de RSU que presentemente cobrem todo o território português, mais de $80 \%$ possuem apenas aterro sanitário e, por conseguinte, não contemplam nem unidades de valorização orgânica nem de incineração, tal facto implica que todos os RSU tenham de ser depositados em aterro, o que implica também desvirtuar toda a política de gestão de resíduos sólidos pois não permite apostar na valorização energética que é considerada uma das grandes mais-valias da adopção dos sistemas integrados de gestão de RSU. Além disso, este quadro actual está claramente distante da actual legislação nacional e comunitária em matéria de valorização e tratamento de resíduos sólidos, nomeadamente na estratégia nacional para a redução da deposição de resíduos urbanos biodegradáveis em aterro; os custos das recolhas selectivas, quer de embalagens, quer de orgânicos, constituem, normalmente, uma das componentes mais dispendiosas do sistema de gestão de resíduos, tanto mais significativa quanto maior for o carácter rural da área em questão, dependendo de factores como a dimensão dos circuitos de recolha selectiva, as distâncias às unidades de triagem ou tratamento, as frequência das recolhas, o peso específico dos resíduos, a informação e educação dos produtores de resíduos, entre outros. Contudo, à semelhança do que já é realizado noutros países, é possível optimizar custos, através de esquemas de recolha em dias alternados, sem duplicação de circuitos ${ }^{21}$ as tecnologias de separação de materiais (tratamentos mecânicos) disponibilizam maior flexibilidade para a gestão do cumprimento de metas de reciclagem material, permitindo evitar esforços praticamente incomportáveis na recolha selectiva de alguns fluxos de resíduos. Refira-se que para além de aspectos económicos, há que ter em consideração os aspectos sociais, nomeadamente os limites da eficiência da participação dos cidadãos (participação e qualidade da participação). Com efeito, por mais que se invista em educação ambiental haverá sempre não aderentes; aos cenários que incluem incineração correspondem custos mais elevados, fundamentalmente decorrentes dos custos de investimento daquele processo. No entanto, não se ignorem as vantagens comparativas daquele processo relativamente a aterros, desde que a montante tenha sido adoptada uma conveniente separação de materiais; qualquer sistema de gestão integrada de resíduos deve ser projectado e gerido por forma a permitir atingir os seguintes objectivos: redução das quan- 
tidades a tratar, máxima recuperação e valorização de materiais (conservação de recursos naturais e de energia), minimização da deposição em aterro, redução de impactes ambientais, sustentabilidade económica e social; um sistema integrado deve englobar todos os tipos de resíduos de idêntica natureza, independentemente da fonte. Por outro lado, qualquer sistema que incorpore reciclagem, compostagem ou tecnologias de valorização energética, está sujeito às condições de mercado e ao desenvolvimento de novas tecnologias, resultantes das imposições legais e da aplicação de instrumentos económicos, pelo que deve ser flexível e orientado para o mercado; o modelo de gestão de resíduos adoptado em Portugal é um modelo repartido por fontes e tipos de resíduos, pelo que dificilmente poderá corresponder a um modelo integrado e razoavelmente sustentado em termos ambientais e económicos. A mesma situação se verifica também quanto à recolha, pois a recolha de RSU indiferenciados e a recolha selectiva e o respectivo tratamento não são, normalmente, realizados pela mesma entidade. Isto significa que, dificilmente, a própria recolha de resíduos pode ser considerada um sistema integrado e sustentado em termos ambientais e económicos; a recolha selectiva de materiais poderá ser substancialmente melhorada se for actuada em três frentes simultaneamente: alterar técnicas de intervenção, apostando numa sensibilização à população e numa educação ambiental muito sérias, abranger o sector comercial e industrial nos programas de recolhas selectivas e investir mais em sistemas de tratamento com capacidade de recuperação de materiais; o actual sistema tarifário de $\mathrm{RSU}$, que na generalidade dos municípios se baseia numa percentagem do valor correspondente ao consumo de água efectuado pelas famílias, não é o mais justo, nem funciona como incentivo à redução e a separação dos resíduos na fonte. É urgente que se avaliem e apliquem sistemas de taxa variável ou tarifas proporcionais à quantidade de resíduos produzidos por cada família. As taxas devem ser calculadas de forma a cobrir total ou parcialmente os custos de recolha e valorização, tratamento ou confinamento, e, simultaneamente, funcionarem como um incentivo à redução. Há referências na literatura a reduções de RSU superiores a $40 \%$, em comunidades que têm em funcionamento sistemas de tarifários proporcionais à quantidade de RSU produzidos por cada família; um outro instrumento económico importante é a implementação de uma taxa de deposição de RSU em aterro desde que complementadas por outros instrumentos, que evitem o desvio de resíduos mistos para incineração. Estas taxas, aplicadas nalguns países europeus, têm-se revelado um bom mecanismo para incentivar a redução de resíduos a depositar em aterro e promover a sua valorização.

\section{MATERIAL SUPLEMENTAR}

Em http://quimicanova.sbq.org.br, com acesso gratuito, estão disponíveis, como complemento ao que foi descrito ao longo do texto, as seguintes figuras e tabelas, em arquivo pdf: Figura 1S: Etapas constituintes de um sistema integrado de RSU. Figura 2S: Fórmula de estrutura geral para os polímeros PEAD e PEBD. Figura 3S: Esquema processual da incineradora de RSU da Valorsul (S. João da Talha, Loures). Figura 4S: Sistema de impermeabilização da célula de deposição das cinzas inertizadas no aterro da Lipor, Porto. Figura 5S: Sistema Integrado de Gestão de RSU da Lipor. Tabela 1S: Fileiras de resíduos a serem depositadas em Ecocentros. Tabela 2S: Características das células de deposição no aterro da Valorsul (Mato da Cruz, V. F. Xira). Tabela 3S: Dados de produção de energia eléctrica do Sistema de Aproveitamento do Biogás do Aterro da Amarsul (Seixal).

\section{AGRADECIMENTOS}

À Dr. ${ }^{a}$ J. Leal, do Centro de Triagem e Ecocentro da Valorsul, Vale do Forno, Lisboa; à Dr. ${ }^{a}$ M. J. Sebastião da Central de Compostagem da Amarsul, Aljeruz, Setúbal; à Eng. ${ }^{a}$ S. Serrano do Aterro Sanitário do Seixal, Amarsul, Seixal e à CTRSU da Valorsul, S. João da Talha, Lisboa.

\section{REFERÊNCIAS}

1. Oliveira, J. F.; Gestão Ambiental, Lidel: Lisboa, 2005.

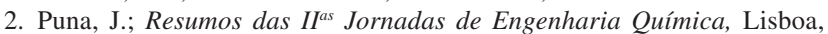
Portugal, 2001.

3. Puna, J.; Proceedings of Encontro Nacional de Engenharia e Gestão Municipal, Porto, Portugal, 2005.

4. http://www.pontoverde.pt/consumidores/consumidores recolha_materiais.html, acessada em Junho 2006.

5. Novais, J.; Métodos biológicos de transformação de resíduos sólidos, CEQB/IST: Lisboa, 1999.

6. http://www.lipor.pt, acessada em Maio 2006.

7. http://www.valorsul.pt, acessada em Maio 2006.

8. Odum, E. P.; Fundamentos de Ecologia, $6^{\mathrm{a}}$ ed, Fundação Calouste Gulbenkian: Lisboa, 2001.

9. Puna, J.; Tese de Mestrado, Universidade Nova de Lisboa, Portugal, 2006.

10. Amarsul; Boletim de Informação da Amarsul 2004, 1, 12.

11. Instituto do Ambiente; Relatório do Estado do Ambiente de 2000, Instituto do Ambiente, Ministério do Ambiente e Ordenamento do Território: Lisboa, Portugal, 2001.

12. Partidário, M. R.; Jesus, J.; Avaliação de Impacte Ambiental, Centro de Estudos de Planeamento e Gestão do Ambiente: Lisboa, 1994.

13. Burchell, R. W.; Listokin, D.; The Environmental Impact Handbook, Center for Urban Policy Research of the State University of New Jersey: New Jersey, 1975.

14. Wathern, P.; Environmental Impact Assessment, Theory and Practice, Routledge: New York, 2000.

15. Vanclay, F.; Bronstein, D.; Environmental and Social Impact Assessment, John Wiley \& Sons: New York, 1995.

16. Pereira, A.; Pinhão, D.; Gonçalves, V.; Tese de Licenciatura, Instituto Superior de Engenharia de Lisboa, Portugal, 2004.

17. Instituto Nacional dos Resíduos; P.E.R.S.U. - Plano Estratégico de Resíduos Sólidos Urbanos, Instituto Nacional dos Resíduos, Ministério do Ambiente e Ordenamento do Território: Lisboa, Portugal, 2000.

18. Instituto Nacional dos Resíduos; Plano de Acção para os RSU 2000-2006 (PERSU), Instituto Nacional dos Resíduos, Ministério do Ambiente e Ordenamento do Território: Lisboa, Portugal, 2000.

19. http://www.inresiduos.pt, acessada em Junho 2006.

20. http://www.iambiente.pt, acessada em Maio 2006.

21. Santana, F.; Ganho, R.; Bilitewski, B.; Martinho, G.; Silveira, A.; Antunes, P.; Cardoso, P.; Estudo Comparativo de Custos de Soluções de Tratamento e Destino Final de Resíduos Sólidos Urbanos - Relatório Final, Faculdade de Ciências e Tecnologia da Universidade Nova de Lisboa, Portugal, 2004.

22. Russo, M.; Tratamento de Resíduos Sólidos, Universidade de Coimbra: Portugal, 2005; http://www.uc.pt/ mhidro/tratamentos_resíduos_sólidos.pdf, acessada em Janeiro 2006.

23. Rocha, I.; Vieira, D.; Resíduos: Legislação, Contencioso ContraOrdenacional, Jurisprudência, Colecção Ambiente, Porto Editora: Porto, 1998.

24. Ferrão, P.; Introdução à Gestão Ambiental. A avaliação do ciclo de vida dos produtos, IST Press: Lisboa, 1998. 
Jaime Filipe Borges Puna* e Bráulio dos Santos Baptista

Departamento de Engenharia Química, Instituto Superior de Engenharia de Lisboa, R. Cons. Emídio Navarro, 1, 1950-062 Lisboa - Portugal

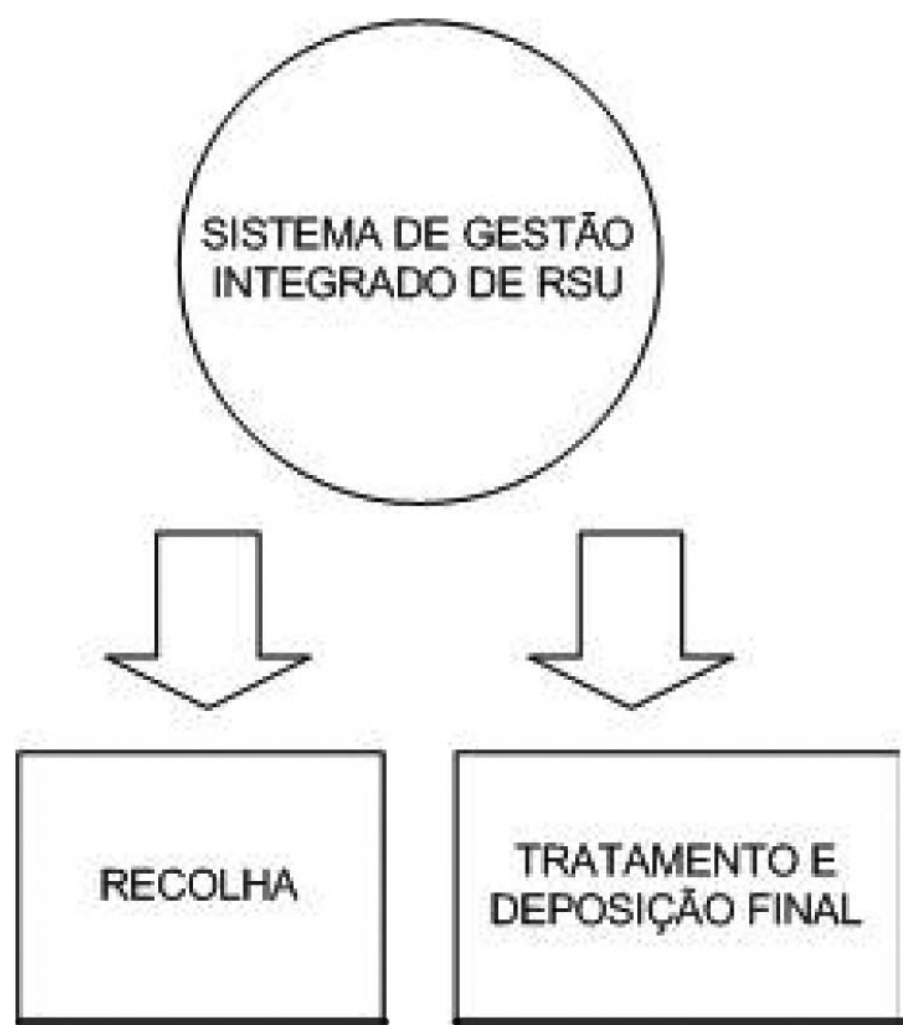

Figura 1S. Etapas constituintes de um sistema integrado de RSU

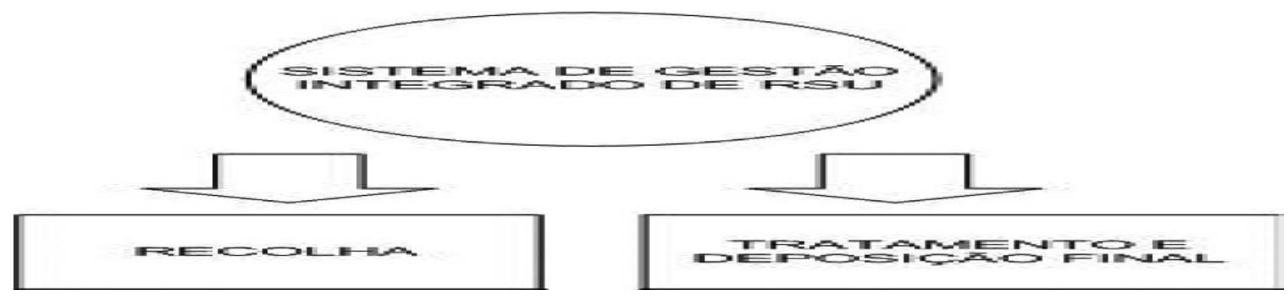

Figura 2S. Fórmula de estrutura geral para os polímeros PEAD e PEBD 
Tabela 1S. Fileiras de resíduos a serem depositadas em Ecocentros Fileira de Resíduo Fluxo semanal Fileira de Fluxo semanal

\begin{tabular}{|c|c|c|c|}
\hline & $\begin{array}{l}\text { médio de } \\
\text { deposição }\end{array}$ & Resíduo & $\begin{array}{l}\text { médio de } \\
\text { deposição }\end{array}$ \\
\hline Papel/Cartão & $2 \mathrm{~m}^{3}$ & Monos & $1 \mathrm{~m}^{3}$ \\
\hline Vidro & $2 \mathrm{~m}^{3}$ & REEE & $1 \mathrm{~m}^{3}$ \\
\hline Plásticos & $2 \mathrm{~m}^{3}$ & Pilhas & $1 \mathrm{~kg}$ \\
\hline Metais & $2 \mathrm{~m}^{3}$ & $\begin{array}{c}\text { Baterias/ } \\
\text { acumuladores }\end{array}$ & 5 unidades \\
\hline Madeira/Paletes & $2 \mathrm{~m}^{3}$ & Óleos usados & $50 \mathrm{~L}$ \\
\hline Resíduos Verdes & $2 \mathrm{~m}^{3}$ & $\begin{array}{l}\text { Lâmpadas } \\
\text { fluorescentes }\end{array}$ & 5 unidades \\
\hline
\end{tabular}

Tabela 2S. Características das células de deposição no aterro da Valorsul (Mato da Cruz, V. F. Xira)

$\begin{array}{lcc}\text { Células de deposição } & \text { 2 células } & 8,6 \mathrm{ha} \\ \text { dos RSU } & & 1.812 .000 \mathrm{~m}^{3} \\ & & 5,0 \mathrm{ha} \\ & & 1.172 .000 \mathrm{~m}^{3} \\ \text { Células de deposição } & 1 \text { célula } & 2,7 \mathrm{ha}^{3} \\ & & 475.000 \mathrm{~m}^{3} \\ \text { das cinzas inertizadas } & \end{array}$

Tabela 3S. Dados de produção de energia eléctrica do Sistema de Aproveitamento do Biogás do Aterro da Amarsul (Seixal)

\begin{tabular}{lc}
\hline Prod. energia eléctrica & População servida \\
\hline $11200 \mathrm{MWh} /$ ano & 4000 famílias \\
$17600 \mathrm{MWh} /$ ano & 5900 famílias \\
\hline
\end{tabular}

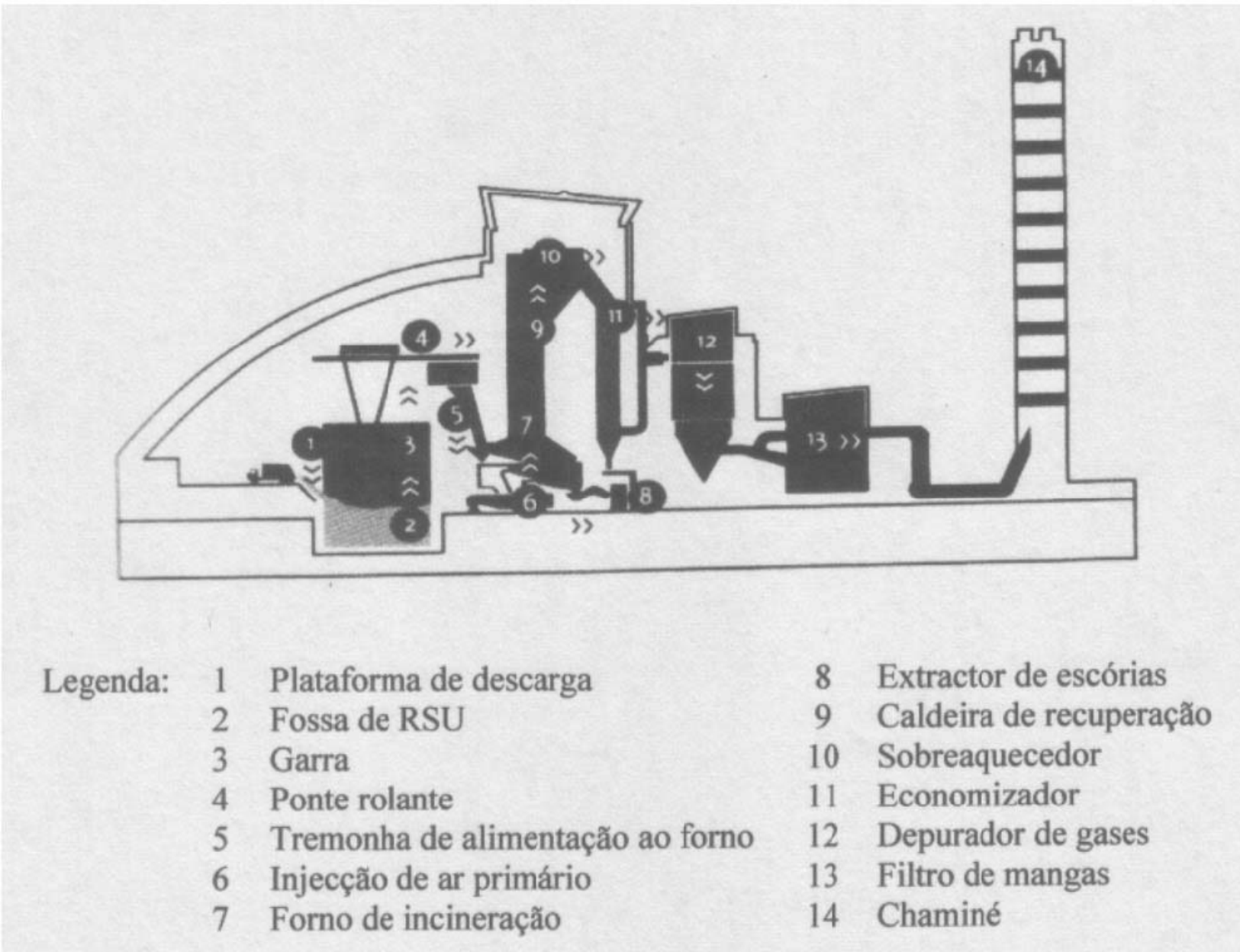

Figura 3S. Esquema processual da incineradora de RSU da Valorsul (S. João da Talha, 


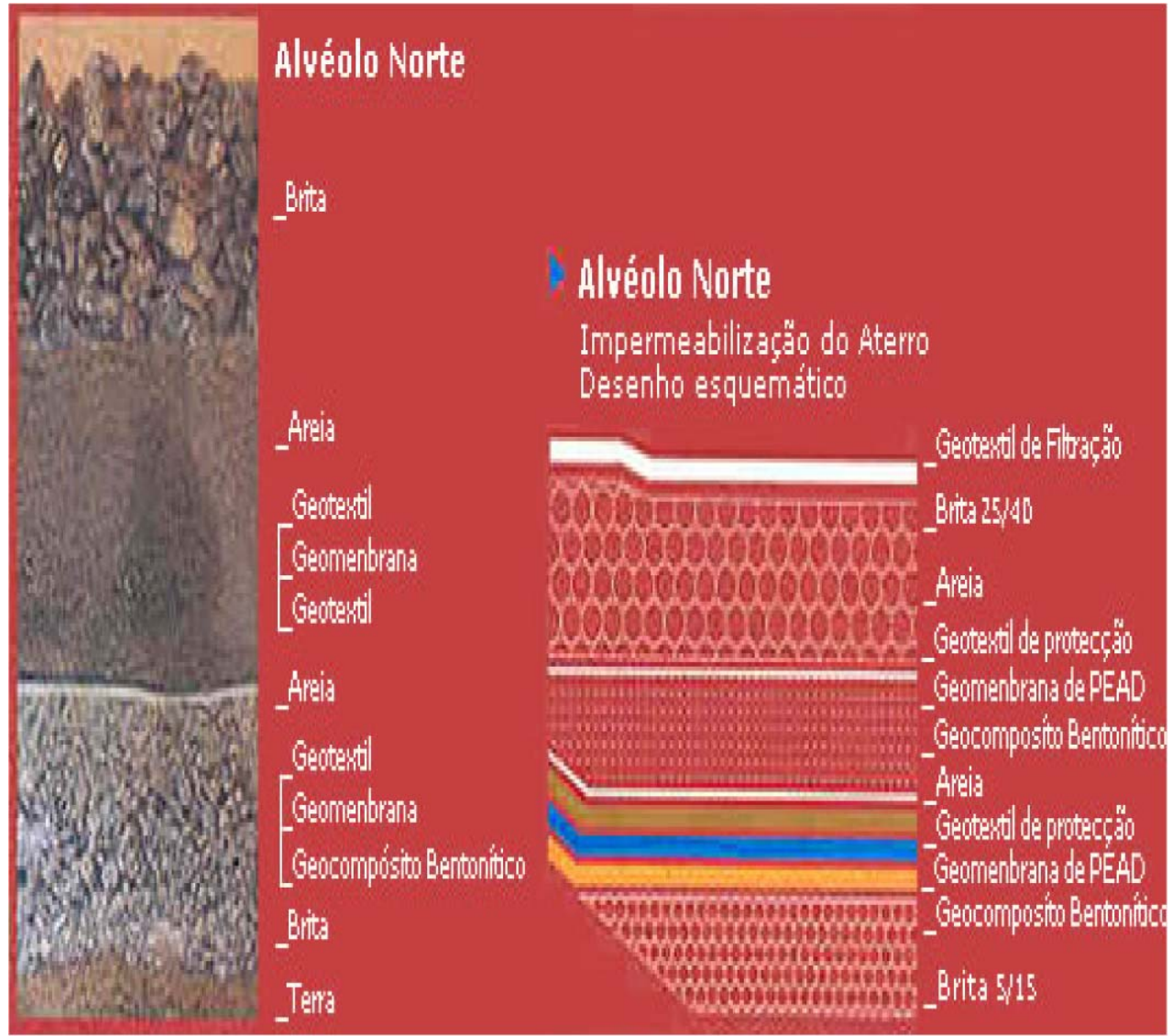

Figura 4S. Sistema de impermeabilização da célula de deposição das cinzas inertizadas no aterro da Lipor, Porto

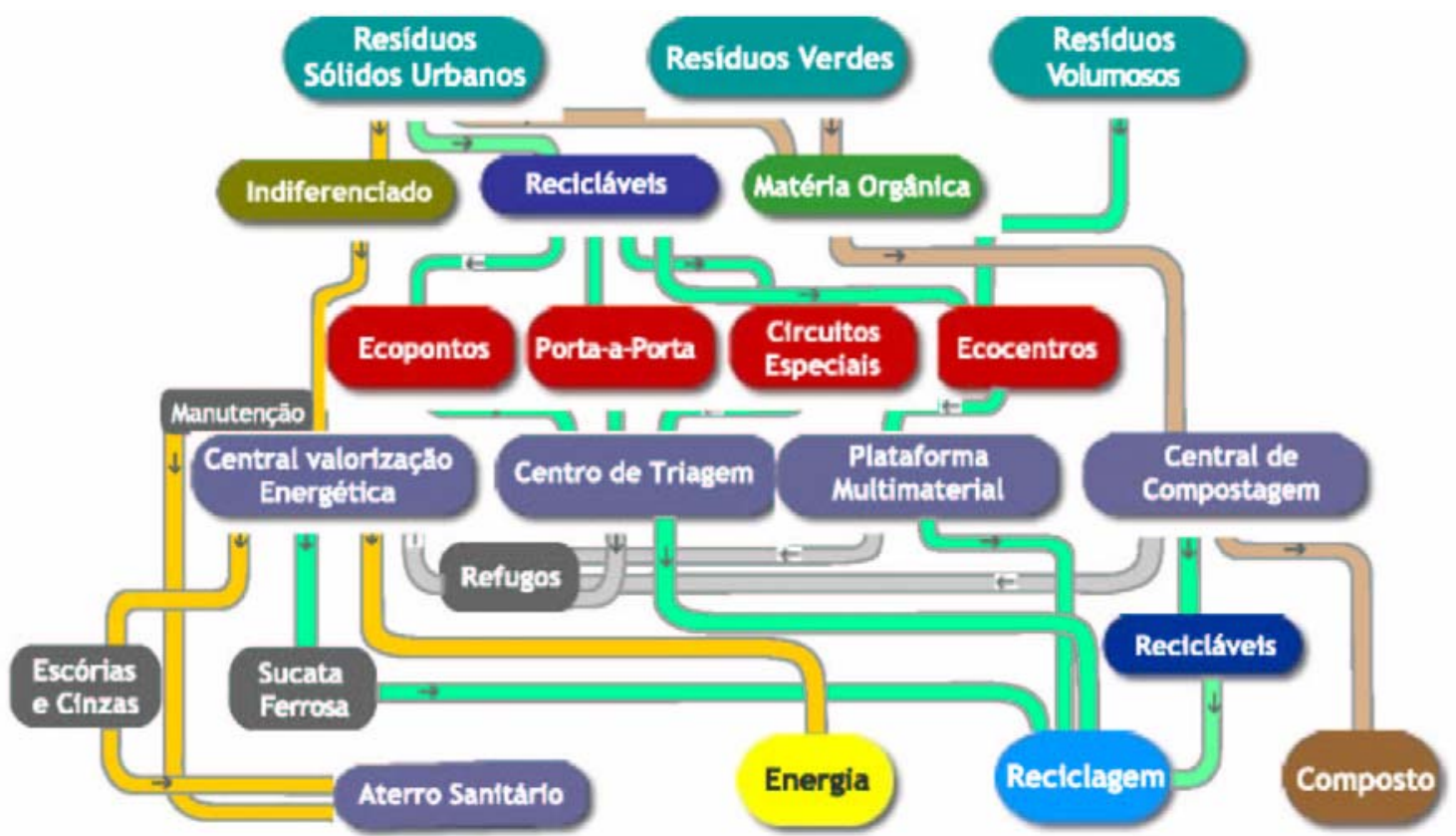

Figura 5S. Sistema Integrado de Gestão de RSU da Lipor 